\title{
Programa Mais Médicos: A formulação de uma nova Política Pública de Saúde no Brasil
}

\section{The "Mais Médicos" Program: The formulation of a new Public Health Policy in Brazil.}

\section{El Programa Más Médicos: La formulación de una nueva Política Pública de Salud en el Brasil.}

Mariele Pena de COUTO ${ }^{1}$

Eneida Desiree SALGADO ${ }^{2}$

Alexsandro Eugenio PEREIRA ${ }^{3}$

RESUMO: O Programa Mais Médicos, ao contratar profissionais médicos para atuar nas regiões prioritárias para o SUS, visa ampliar o acesso da população à atenção básica de saúde. Este estudo resgata o processo de formulação deste programa, pela perspectiva do Modelo de Múltiplos Fluxos, desenvolvido por John Kingdon, com ênfase nos embates estabelecidos entre os Poderes Executivo e Legislativo. Analisa, ainda, a Exposição de Motivos Interministerial n. ${ }^{\circ}$ 024/2013-MS/MEC/ MP, a Medida Provisória n. ${ }^{\circ}$ 621/2013 e o Projeto de Lei de Conversão n. ${ }^{\circ}$ 026/2013-CN que culminaram na edição da Lei n. ${ }^{\circ} 12.871 / 2013$. Ao final, são apresentados resultados pontuais para explicitar a perenidade da agenda governamental de saúde pública nacional frente à atuação dos atores envolvidos neste processo e seus interesses e estratégias aplicados com o objetivo de influenciar os decisores políticos para a formulação do Programa.

Palavras-Chave: Políticas Públicas. Saúde Pública brasileira. Política de saúde. Programa Mais Médicos. Processo Legislativo.

ABSTRACT: The "Mais Médicos" (More Doctors) Program hires doctors to work in "SUS" (Single Healthy System - the Brazilian public health system) priory regions aiming to increase the population's access to basic health care. This study rescues this program formulation process, from the perspective of the Multiple Stream Model developed by John Kingdon, emphasizing on 1 Doutoranda e Mestre em Políticas Públicas pela UFPR. Especialista em Gestão Pública com habilitação em Políticas Públicas pelo IFPR e em Ministério Público - Estado Democrático de Direito pela UNIBRASIL/FEMPAR. Graduada em Direito pela UNIBRASIL. Servidora do Tribunal de Justiça do Estado do Paraná. Email: marielecouto@gmail.com 2 Doutora e Mestre em Direito do Estado pela Universidade Federal do Paraná. Pós-doutorado realizado no Instituto de Pesquisas Jurídicas da Universidade Nacional Autônoma do México. Professora do Departamento de Direito Público e dos Programas de Pós-Graduação em Direito e em Políticas Públicas da UFPR. Pesquisadora e vice-líder do Núcleo de Investigações Constitucionais da UFPR. Email: desiree@ufpr.br

3 Doutor e Mestre em Ciência Política pela Universidade de São Paulo (USP). Professor do Departamento de Ciência Política e Sociologia e dos Programas de Pós-Graduação em Ciência Política e em Políticas Públicas da Universidade Federal do Paraná (UFPR). Email:alexsep@ufpr.br 
the debate established between the Executive and the Legislative branches in the moment of its formulation. It also analyzes the Explanatory Memorandum number 024/2013-MS/MEC/MP, the Conversion Act number 621/2013 and the Conversion act project number 026/2013-CN which have culminated in the Law number 12.871/2013. In the end of this work results are presented to explicit the National Public Healthy Government Agenda perpetuity regarding the performance of the ones involved in this process, as well as their interests and strategies applied in order to influence policy makers in the program formulation.

Keywords: Public Policy. Brazilian Public Health. Health Policy. Mais Médicos Program. Legislative Process.

RESUMEN: El programa más médicos, en la contratación de médicos para trabajar en regiones prioritarias para el Sistema Único de Salud, tiene como objetivo aumentar el acceso de la población a la atención básica del servicio de salud. En este estudio se delineará el proceso de formulación de dicho programa desde el enfoque de flujos o corrientes múltiples propuesto por John Kingdon, con énfasis en los conflictos que se establecen entre los poderes ejecutivo y legislativo al momento de su formulación. Se analiza también la exposición de motivos realizada conjuntamente por los Ministerios de Salud, Educación y Público Federal (No 024/2013-MS/MEC/MP), la medida provisoria n. ${ }^{\circ}$ 621/2013 y el Proyecto de Ley de conversión N. ${ }^{\circ}$ 026/2013-CN, el cual culmino en la edición de la Ley N. ${ }^{\circ}$ 12.871/2013. Al final, se presentan los resultados apuntando a explicar la continuidad de la agenda gubernamental de salud pública nacional, el desempeño de los actores involucrados en el proceso de creación y formulación del programa, así como sus intereses y estrategias utilizadas para influir sobre los tomadores de decisión política.

Palabras Claves: Políticas Públicas.Salud Pública Brasileña. Programa Más Médicos. Proceso Legislativo.

\section{INTRODUÇÃO}

A saúde pública brasileira sempre se posicionou na periferia dos temas recorrentes no cenário nacional, seja no que tange à formulação e implementação de ações destinadas a atender aos direitos sociais, seja no que concerne aos recursos públicos direcionados para tal finalidade. Porém, desde a promulgação da Constituição de 1988 - que ampliou o conceito de saúde e determinou a universalização do atendimento - o sistema de saúde vem passando por um processo de reformas que pode ser analisado a partir da formulação do Programa Mais Médicos.

Este artigo destina-se a apresentar algumas reflexões decorrentes da análise aplicada à fase prédecisória da formulação do Programa Mais Médicos, estruturada com base no Modelo de Múltiplos Fluxos, desenvolvido por John Kingdon. Para tanto, será enfatizada a atuação dos agentes políticos participantes do processo legislativo que influenciaram no rol de opções políticas disponíveis para a tomada de decisão relativa ao Programa. 
A remodelação desta agenda governamental perpassa os embates travados entre os Poderes Legislativo e Executivo, por meio da investigação da Exposição de Motivos Interministerial (EIM) n. ${ }^{o}$ 24/2013-MS-MEC-MP, da Medida Provisória (MPV) n. ${ }^{o}$ 621/2013 e do Projeto de Lei de Conversão (PLV) n. ${ }^{\circ}$ 26/2013-CN.

Este artigo é composto por cinco seções, além da introdução e das considerações finais. Asegundaseção evidencia, o Modelo de Múltiplos Fluxos e seus componentes (fluxos de problemas, de soluções e de política). Aterceiraseção apresenta uma contextualização do sistema de saúde brasileiro e aponta o Programa Mais Médicos como um método hábil, no entender dos agentes políticos, para enfrentar diversos problemas da saúde pública. Aquartaseção debruça-se sobre os trabalhos finais inerentes ao processo legislativo que culminou na confluência dos múltiplos fluxos para a formulação do Programa Mais Médicos.

\section{O MODELO DE MÚLTIPLOS FLUXOS COMO INSTRUMENTAL PARAAANÁLISE DA FORMULAÇÃO DE POLÍTICAS PÚBLICAS NO BRASIL}

O Modelo de Múltiplos Fluxos, desenvolvido por John Kingdon é um aperfeiçoamento do modelo lata de lixo (garbage can) apresentado por Cohen, March e Olsen, segundo os quais as soluções postas às demandas sociais são anteriores à definição de uma questão como problema ${ }^{1}$. Kingdon, por sua vez, concebeu sua pesquisa para acompanhar o desenvolvimento das políticas públicas ao longo do tempo, concentrando-se nas áreas de saúde e de transporte do governo federal dos Estados Unidos, com ênfase na distinção entre a agenda governamental e a agenda decisória ${ }^{2}$.

Para tanto, Kingdon pressupõe que a formulação de políticas públicas decorre de um conjunto de processos compostos pela (1) definição da agenda; (2) especificação de alternativas a partir das quais as escolhas devam ser feitas; (3) tomada de decisão pela autoridade entre as alternativas específicas, e; (4) implementação da decisão. O sucesso num dos processos não implica, necessariamente, no sucesso dos demais ${ }^{2}$

Kingdon aprofunda seus estudos sobre os dois primeiros processos, configuradores do estágio pré-decisório, quais sejam: aformação da agenda governamental (agenda-setting) e as alternativas para a formulação das políticas (policy formulation). A partir desses elementos, o autor evidencia as razões pelas quais é atribuída relevância a determinadas questões que adentram a agenda política e se tornam proeminentes em detrimento de outras. Como resultado deste trabalho é possível entender o motivo pelo qual algumas alternativas são seriamente consideradasenquanto outras são negligenciadas ou desprezadas ${ }^{2}$. Para além disso, Kingdon busca compreender não só como a agenda é composta ao longo do tempo, mas como e por que ela muda de uma hora para a outra ${ }^{3}$.

Assim, a geração de alternativas está mais voltada à área de atuação dos especialistas, enquanto a relevância da definição dos problemas que compõem a agenda atrela-se a uma atribuição presidencial ${ }^{2}$. Nesse aspecto, o chefe do Poder Executivo pode dominar as discussões que 
comporão a agenda e os membros do Congresso Nacional possuem maior capacidade de elaborar as alternativas possíveis, reduzindo, neste campo, o controle presidencial ${ }^{3}$.

Portanto, Kingdon trabalha com duas categorias de fatores que podem influenciar a definição da agenda e a especificação de alternativas: $i$ ) os participantes ativos (a presidência, os membros do Congresso Nacional, os burocratas do Poder Executivo e várias forças externas ao governo, como a mídia, os grupos de interesses, os partidos políticos e o público em geral); eii) os processos pelos quais os itens da agenda e as alternativas entram em destaque ${ }^{2}$.

Além de buscar entender a relação estabelecida entre os participantes, é relevante compreender o processo pelo qual a agenda é definida e como são especificadas as alternativas. Este processo pode ser de três tipos: problemas (problem), alternativas ou soluções políticas (policies) e processo político (politics), os quais formam a estrutura de três fluxos dinâmicos: $\boldsymbol{i}$ ) o fluxo de problemas (problem stream); ii) o fluxo de alternativas ou soluções (policy stream); e iii) o fluxo de política (political stream), representado na Figura $1^{2}$.

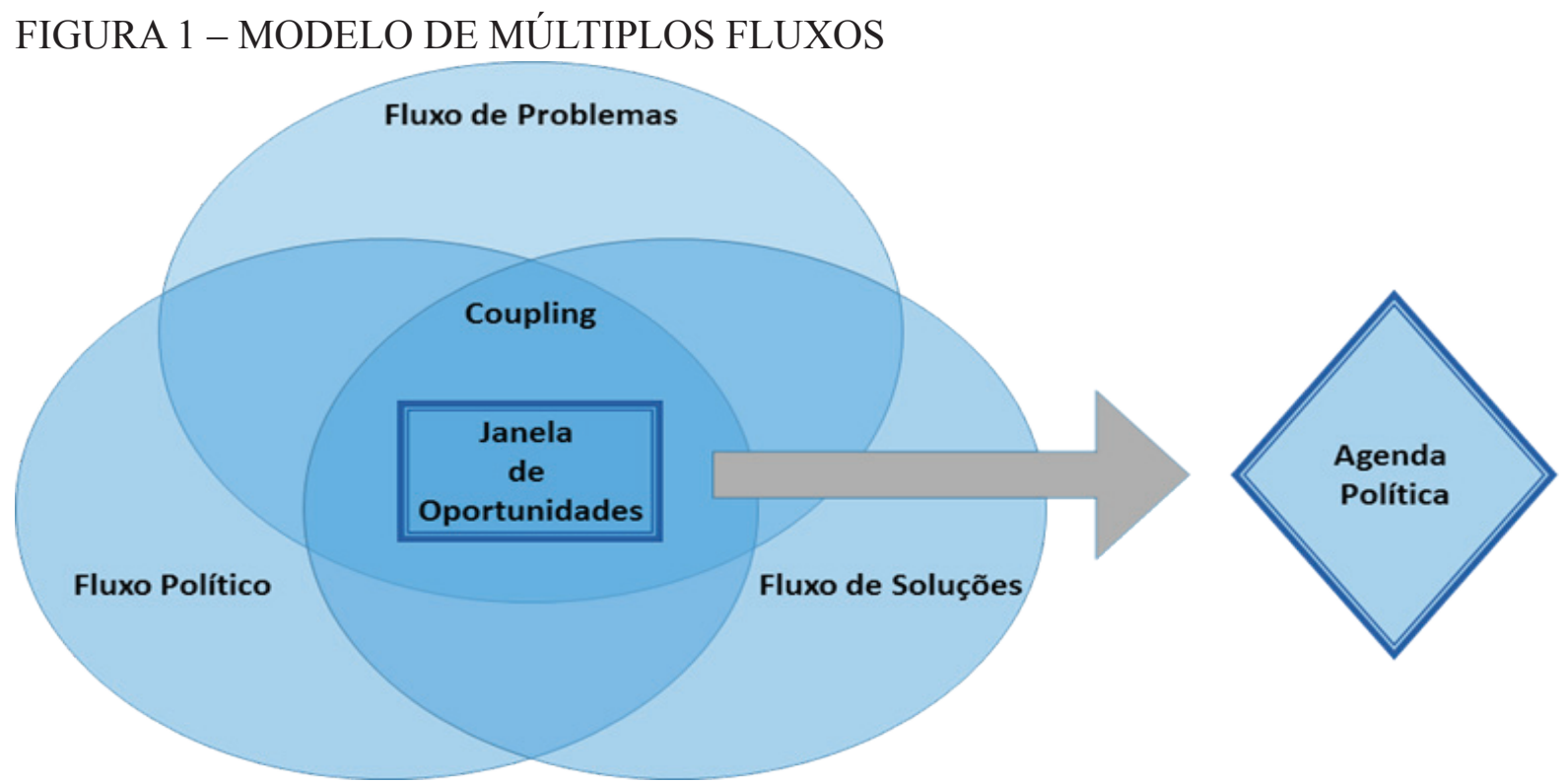

Fonte: Os Autores (2015) com base em Kingdon (2013).

Nesse contexto, o fluxo de problemas é compreendido como um conjunto de informações sobre uma variedade de questões relacionadas à atuação do Estado e consideradas controversas, ambíguas, instáveis ou pendentes de solução; o fluxo de soluções é o ambiente onde se concentram as especificações de alternativas a partir das quais as escolhas serão tomadas com vistas a sanar o problema evidenciado; e o fluxo de política é composto pelo estado de espírito público, pelas campanhas dos grupos de pressão, pelos resultados eleitorais, pelas distribuições partidárias ou ideológicas do Congresso nacional e pelas mudanças de administração, com poderoso efeito sobre a agenda, a proeminência de novos temas e o arquivamento de outros, pelas mais variadas razões. Compete destacar, desde logo, que os referidos fluxos fluem separadamente e, quando se acoplam (coupling), permitem a elevação do tema à agenda política e uma possível tomada de decisão ${ }^{2}$. 
No âmbito do fluxo de política, a influência dos agentes políticos está atrelada a questões como a oscilação do humor nacional, as imprecisões da opinião pública, os resultados das eleições, as mudanças na administração e o volume de negócios no Congresso.O "clima" ou "humor" nacional (national mood) consiste na percepção, pelos participantes do processo decisório, sobre o humor favorável à consecução das ações destinadas à promoção de determinadas questões ou, inclusive, à prática de atos voltados a desestimular determinadas ideias, afetando diretamente a agenda ${ }^{2}$.

O humor nacional apresenta-se, ao mesmo tempo, como propulsor e opressor dos temas, ao elevá-los, ou não, à agenda governamental. Sua oscilação é considerada tão inevitável quanto o movimento de um pêndulo, cujo deslocamento influirá diretamente no fluxo de política que se moverá para a esquerda num determinado ponto do tempo e, na sequência para a direita, em sintonia com o humor nacional ${ }^{2}$.

Em síntese, o Modelo de Múltiplos Fluxos visa investigar três questões basilares, quais sejam: i) Como os problemas captam a atenção dos atores, são determinados e modelados; ii) Como e quando é conduzida a busca por soluções; e iii) Como os tomadores de decisão voltam suas atenções para determinados problemas e decisões. Pretende-se investigar estas questões ao longo das próximas seções deste artigo.

\section{OS FLUXOS DE PROBLEMAS, DE SOLUÇÕeS E DE POLÍTICAS NA SAÚde PÚBLICA BRASILEIRA}

O estudo sobre a formulação do Programa Mais Médicos e sua inserção na agenda governamental de saúde brasileira decorre de um recorte temático relativo a gama de conteúdos que integram a saúde pública nacional. Metodologicamente, por força da recente implementação do Programa, é impossível abordá-lo globalmente, pela ótica de todas as etapas que integram o ciclo da política pública.

Isso justifica a delimitação temática empregada para analisar, tão somente, a etapa pré-decisória de formulação do Programa Mais Médicos, especialmente em decorrência do processo de revisão, modificação e adaptação permanente deste programa, integrada ao contexto dos arranjos políticos e administrativos decorrentes das demandas sociais e das atuações políticas.

Portanto, esta limitação serve como estímulo à compreensão de um Programa de Saúde Pública de longo alcance de forte impacto no cenário da política pública nacional, que por estas adjetivações, além da complexidade que lhe é inerente, merece ser compreendido de forma gradual.

\subsection{A PERENIDADE DA AGENDA DE REGULAMENTAÇÃO DA SAÚdE PELA PERSPECTIVA DO FLUXO DE PROBLEMAS}

A premência e a recorrência do problema identificado de insuficiência de profissionais médicos para atendimento junto à atenção básica de saúde pública brasileira encontram-se atreladas à 
concepção constitucional de direito universal à saúde, enquanto dever a ser cumprido pelo Estado 4 . Portanto, é desde a instituição do Sistema Único de Saúde (SUS), há mais de 26 anos, que se reconhece a incapacidade do Estado em prover o atendimento médico a todos os cidadãos 5 .

A análise da (re)emergência deste problema junto à agenda governamental de saúde brasileira, pela perspectiva do Modelo de Múltiplos Fluxos $^{2}$, perpassa a apreciação das alternativas e soluções apresentadas pelos agentes políticos, bem como a interpretação conferida por eles ao humor nacional, marcado pelas Manifestações de Junho de 2013 enquanto catalizador da multipolarização dos interesses coletivos e desencadeador das ações implementadas pelos Poderes do Estado ${ }^{2,6,7,8}$.

Desse modo, seguindo a perspectiva teórica adotada, a perenidade desta agenda política, pertinente à escassez de profissionais médicos para o atendimento primário do SUS à população carente ou estabelecida em lugares remotos, tornou-se visível e reemergiu como problema pendente de solução, carecendo da formulação de uma política pública, a partir da interpretação conferida pelos agentes políticos às mobilizações de junho de 2013.

\subsection{A DINÂMICA EXERCIDA PELOS PODERES EXECUTIVO E LEGISLATIVO PARA A ARTICULAÇÃO DO FLUXO DE SOLUÇÕES}

O fluxo de soluções constitui o ambiente onde as alternativas são apresentadas, vinculadas ou não a um problema previamente identificado. No momento em que um problema é posto em evidência, as opções colocadas em discussão serão utilizadas como forma de mitigá-lo.Segundo Kingdon, a fase de geração de propostas políticas assemelha-se a um processo de seleção biológica natural, onde as ideias e possibilidades flutuam num "caldo primitivo de políticas" (policy primeval soup $)^{2}$. No caso do Programa Mais Médicos, o processo pelo qual as propostas foram geradas, debatidas, reformuladas e aceitas, foi desenvolvido por um grupo coeso, formado inicialmente pelos ministros da Saúde, da Educação e do Planejamento.

A proposta apresentada por estes atores através da EIM n. ${ }^{\circ}$ 24/2013-MS-MEC-MP visou atender a vários critérios, tais como a viabilidade técnica e orçamentária, entre outros. Cumprir estes requisitos é essencial para obter a aquiescência da Presidência da República e o consenso da sociedade em geral sobre a necessidade da formulação do Programa nos moldes apresentados?.

Segundo se infere da EIM em análise, o escopo pretendido com a formulação do Programa é atender aos princípios e diretrizes estabelecidos em relação à saúde, tais como a universalização, a equidade, a integralidade da atenção, a regionalização, a descentralização, a hierarquização e a participação, especialmente porque a Constituição Federal, em seu artigo 200, III, confere ao SUS

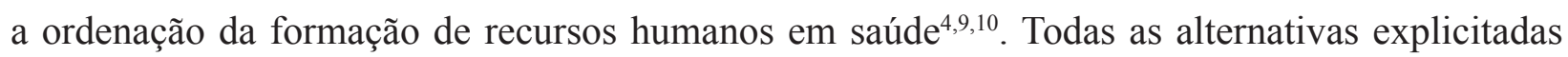
foram encampadas pela Presidente da República, Dilma Rousseff ao editar, em 09 de julho de 2013, a MPV n. ${ }^{\circ}$ 621/2013 que, como o próprio nome diz, "constitui espécie normativa despida de eficácia permanente" ${ }^{11,12}$. 
A Presidência da República objetivou incutir sobre a percepção social um elemento justificador ao acolhimento dos argumentos lançados na EIM n. ${ }^{\circ}$ 24/2013-MS-MEC-MP para a edição da MPV $n^{0}$ 621/2013, valendo-se da atribuição de um significado legitimador tanto à construção da EIM quando ao acolhimento das propostas nela inseridas. Pode-se atribuir a esses atos uma conotação de conformidade e adequação ao atendimento dos clamores sociais que teriam exigido ações, prontas e rápidas, para questões particularizadas. Em outros termos, o Poder Executivo interpretou as Manifestações de Junho de 2013 como uma onda de mobilizações sociais causadora da (re) emergência dos problemas relacionados à necessidade de ampliação do acesso à saúde ${ }^{13,14}$. Isto, ao que parece, e pela perspectiva do Modelo de Múltiplos Fluxos ${ }^{2}$, permitiu a abertura de uma janela de oportunidades com força capaz de confluir os múltiplos fluxos, tornando o solo fértil para a formulação do Programa Mais Médicos, conforme será evidenciado no próximo tópico.

Por ora, destaca-se a noção de que o ato emanado pela Presidência da República ressalta a relevância atribuída ao ocupante do cargo de Chefe do Poder Executivo que, sozinho, pode definir a agenda não só interna do Poder Executivo, como também externa, atribuída aos membros do Poder Legislativo, ao forçar a análise, pelo Congresso Nacional, de questões consideradas urgentes e relevantes ${ }^{15}$.

Porém, políticas públicas e programas governamentais não são criação de um ator isolado. A iniciativa de uma alternativa pode vir de qualquer lugar. Logo, o fator crítico não reside em explicar a proeminência de um item na agenda em razão de sua fonte, mas em avaliar o clima no governo ou a receptividade das ideias apresentadas ${ }^{2,16}$.

Portanto, em decorrência dos atos propulsores gerados pelo Poder Executivo, o Congresso Nacional foi compelido a apreciar o tema inerente à formulação do Programa Mais Médicos, conforme enunciado na Mensagem n.$^{\circ}$ 276/2013 ${ }^{17,18}$.

\subsection{O DESVENDAR DO PROCESSO LEGISLATIVO E A ATUAÇÃO CONGRESSUAL PARA A CONVERGÊNCIA DOS FLUXOS}

O estabelecimento das agendas pelo Congresso Nacional, segundo o entendimento de Kingdon, torna essa instituição repositório de inúmeras responsabilidades constitucionalmente estabelecidas e objeto de atenção da mídia e do público ${ }^{2}$ e, ao mesmo tempo, produtora de 594 agendas individuais incapazes de coordenação por ausência de controle sobre as execuções ou por deficiência na capacidade de elaboração de propostas detalhadas.

As agendas em referência opõem-se ao recurso organizacional do Poder Executivo, constituídopor uma entidade de decisão unitária. No Congresso Nacional 594 membros (513 Deputados Federais e 81 Senadores) operam 594 agendas, cada uma com um pouco de crédito sobre a instituição, onde alguns dos membros são mais importantes que outros, além de que no Congresso não existem mecanismos de coordenação ou incentivo de cooperação comparável com aqueles que operam no 
Poder Executivo. Por isso, os parlamentares podem estar à mercê de grupos de interesses, círculos eleitorais e pressões da administração, impedindo-os de estabelecer uma agenda própria.

As medidas provisórias, uma vez editadas, estão sujeitas à deliberação do plenário das Casas Parlamentares, que apreciarão aspectos formais e materiais, inclusive de constitucionalidade da norma extraordinária, tornando este ato originariamente precário e provisório em regra estável e duradoura ${ }^{19,20,21}$. No caso em exame, a dinâmica exercida pelo Congresso Nacional restou consolidada no PLV n. ${ }^{\circ}$ 26/2013-CN.

No âmbito das Políticas Públicas, o fluxo de política caracteriza-se por promover ou inibir o status da agenda política. Todos os atores importantes no sistema (não apenas os políticos) são capazes de julgar se o equilíbrio de forças estabelecido dentro do fluxo favorecerá as ações que se pretende desenvolver ou não. Estes atores também são qualificados para avaliar se o público está apto a, ao menos, tolerar as direções que pretendem seguir sobre determinado tema, pois caso isso não ocorra, certamente recuarão em suas ações².

É exatamente neste contexto que circularam as proposições de emendas apresentadas pelos parlamentares em relação ao PLV n. ${ }^{o}$ 26/2013-CN. Os parlamentares, além de realizarem o controle sobre as ações exercidas unilateralmente pela chefia do Poder Executivo, também apresentam alternativas por eles consideradas mais adequadas para sanar o problema evidenciado, inclusive, com o objetivo de otimizar a MPV n. ${ }^{\circ} 621 / 2013$.

Para análise, as proposições de emenda foram classificadas em áreas, definidas pelos autores, com base nos capítulos e nos temas correlatos que compõem a Medida Provisória $n^{0}$ 621/2013, acompanhada da síntese da justificativa ofertada pelo parlamentar, cuja exposição se pautará numa correlação do maior para o menor número de proposições de emendas apresentadas, com base na seguinte organização:Área 1 - Capítulo IV - Do Projeto Mais Médicos para o Brasil (artigos $7^{\circ}$ a 16); Área 2 - Capítulo III - Da formação médica no Brasil (artigos $4^{\circ}$ a $6^{\circ}$ ); Área 3 - Capítulo II Da autorização para funcionamento de cursos de medicina (artigo $3^{\circ}$ ); Área 4 - Novos dispositivos; Área 5 - Capítulo V - Disposições Finais (artigos 17 a 27); Área 6-Outras leis; Área 7 - Capítulo I - Disposições Gerais (artigos $1^{\circ}$ e $2^{\circ}$ ); Área 8 - Exame Nacional de Revalidação de Diplomas Médicos (REVALIDA);Área 9 - Prestação de serviço militar obrigatório; Área 10 - Alteração da Lei n. ${ }^{\circ}$ 10.260/2001; Área 11 - Ementa.

As variáveis foram apreciadas com a utilização do software Gephi ${ }^{22}$, com a finalidade de tornar mais amistosa a visualização do cruzamento dos dados e facilitar a análise de ligação entre os parlamentares, partidos políticos, áreas de assunto, oriundos do Projeto de Lei de Conversão n. ${ }^{\circ}$ 26/2013-CN, conforme adiante demonstrado, em gráficos de rede de modelo circular.

A análise do PLV n. ${ }^{\circ}$ 26/2013-CN permitiu identificar a apresentação de 567 emendas parlamentares, as quais contemplam 1733 proposições.O principal tema de articulação entre os parlamentares cinge-se ao Projeto Mais Médicos para o Brasil (referenciado no capítulo IV da 
MPV n. ${ }^{\circ}$ 621/2013 - área 1). Todavia, constata-se que as duas questões subsequentes - formação médica no Brasil (referenciado no capítulo III da MPV n. ${ }^{\circ}$ 621/2013 - área 2) e autorização para o funcionamento no curso de medicina (referenciado no capítulo II da MPV n. ${ }^{0}$ 621/2013 - área 3) - se somadas, superam a discussão travada sobre o tema principal ${ }^{18}$.

Conquanto os decisores políticos tenham atribuído grande relevância ao Programa Mais Médicos, extrai-se, ainda, que os parlamentares representantes dos estados de Alagoas (AL), Amapá (AP), Mato Grosso (MT) e Pará (PA) estiveram fora das discussões do PLV n. ${ }^{\circ}$ 26/2013CN. Considerando-se, ainda, a questão relativa às proposições de emendas por Unidade Federativa, a respeito do tema principal (área 1), quatro estados permaneceram inertes, quais sejam: Tocantins (TO), Bahia (BA), Piauí (PI) e Rondônia (RO). Por outro lado, o segundo tema mais discutido (área 2), apenas dois estados não se manifestaram: Amazonas (AM) e Acre (AC). Esse dado evidencia uma maior preocupação dos atores envolvidos com o processo de formação médica do que com o escopo do programa voltado à ampliação do acesso da população aos profissionais médicos ${ }^{18}$.

Constata-se que os estados do Maranhão (MA), da Bahia (BA) e o Distrito Federal (DF) limitaram suas manifestações apenas em relação aos três primeiros temas mais discutidos (áreas 1 a 3). O DF restringiu-se aos dois primeiros temas (Áreas 1 e 2) e a BA apenas ao segundo tema (Área 2). Em contrapartida, o estado de SP foi o que ofertou sugestões em relação ao maior número de temas, ao apresentar proposições que se espraiam por quase toda a MPV n. ${ }^{0} 621 / 2013^{18}$.

Ofertaram proposições de emendas os atores filiados aos seguintes partidos políticos: Democratas (DEM); Partido Comunista do Brasil (PCdoB); Partido Democrático Trabalhista (PDT); Partido Ecológico Nacional (PEN);Partidodo Movimento Democrático do Brasil (PMDB); Partido Progressista (PP); Partido Popular Socialista (PPS); Partido da República (PR); Partido Republicano Brasileiro (PRB); Partido Social Cristão (PSC); Partido Social Democrático (PSD);Partido da Social Democracia Brasileira (PSDB); Partido dos Trabalhadores (PT); Partido Trabalhista Brasileiro (PTB); Partido Verde (PV) ${ }^{18}$.

Não participaram dos embates atinentes ao principal tema (Área 1) os atores filiados ao PEN e PDT. No segundo tema (Área 2) houve a participação de atores filiados a todos os partidos políticos envolvidos. Por fim, em relação à Área 3, atores filiados a cinco partidos políticos não se manifestaram: PDT, PEN, PP, PR e PRB ${ }^{18}$.

Ressalta-se que as ligações mais fortes estabelecidas em relação ao principal tema (área 1) decorrem dos atores filiados ao PSDB (160 proposições apresentadas), PMDB (125 proposições apresentadas) e DEM (114 proposições apresentadas). Esta análise revela a participação de grupos de oposição (DEM e PSDB) e da base do governo (PMDB) pretendendo, de alguma forma, alterar os dispositivos inicialmente apresentados pelo Poder Executivo ${ }^{18}$. 
Essa conjuntura evidencia a força que permeia as articulações políticas desenvolvidasna defesa de interesses dos atores que atuam conjuntamente, tendo por escopo a formulação de propostas similares ou idênticas com o objetivo de influenciar o rol de opções políticas colocadas à disposição dos tomadores de decisão.

Apesar do grande número de proposições de emendas apresentadas, considerando a integralidade dos assuntos tratados no PLV n. ${ }^{\circ}$ 26/2013-CN, a sua maioria, equivalente a 78,48\%, foi rejeitada, enquanto apenas 19,45\% foram acolhidas. O DEM foi o partido político com o maior número de acolhimento das proposições de emendas apresentadas, totalizando 84 acolhimentos; seguido do PMDB, com 66 proposições de emenda acolhidas, e do PSDB, perfazendo o montante de 64 acolhimentos ${ }^{18}$.

Conquanto esses números, o maior índice de acolhimento em relação ao quantitativo de proposições apresentadas foi de 41,46\%, obtido pelo PPS, e este percentual corresponde ao acolhimento de 34 proposições. O DEM foi o segundo partido com o maior número de proposições de emendas admitidas, ao satisfazer $30,32 \%$ de suas pretensões. Por conseguinte, o PTB foi contemplado com o acolhimento de 29,31\% de suas proposições, obtendo êxito em 17 propostas oferecidas $^{18}$.

Verifica-se, ainda, uma atuação conjunta dos parlamentares atuantes no PLV n. ${ }^{\circ}$ 26/2013-CN. Desta articulação extrai-se a existência, de aspirações, ideias, concepções e pretensões comuns entre alguns dos congressistas atuantes neste PLV. Esse compartilhamento visa fortalecer a realização de objetivos comuns, no sentido de satisfazer as pretensões desta coletividade identificada, cuja atuação conjunta afasta a fraqueza que permeia a influência individual na participação política.

A atuação conjunta dos parlamentares é inerentes ao sistema democrático e decorrem da identificação de propósitos com vistas ao alcance das finalidades comuns a esta coletividade ${ }^{18,23}$.

A identificação da atuação conjunta dos parlamentares no PLV n. ${ }^{\circ}$ 26/2013-CN decorreu da análise da justificativa contida em cada uma das proposições de emendas apresentadas, mediante o agrupamento das justificativas similares ou idênticas. Esta forma de atuação confere à participação dos congressistas envolvidos uma aparente formação de grupos de interesses. Destaque-se, porém, que os partidos PP, PT, PRB, PSC, PR e PDT, embora tenham apresentado proposições de emenda, suas justificativas foram inéditas, se comparado com os demais partidos que compõem os grupos de interesses ${ }^{18}$. 


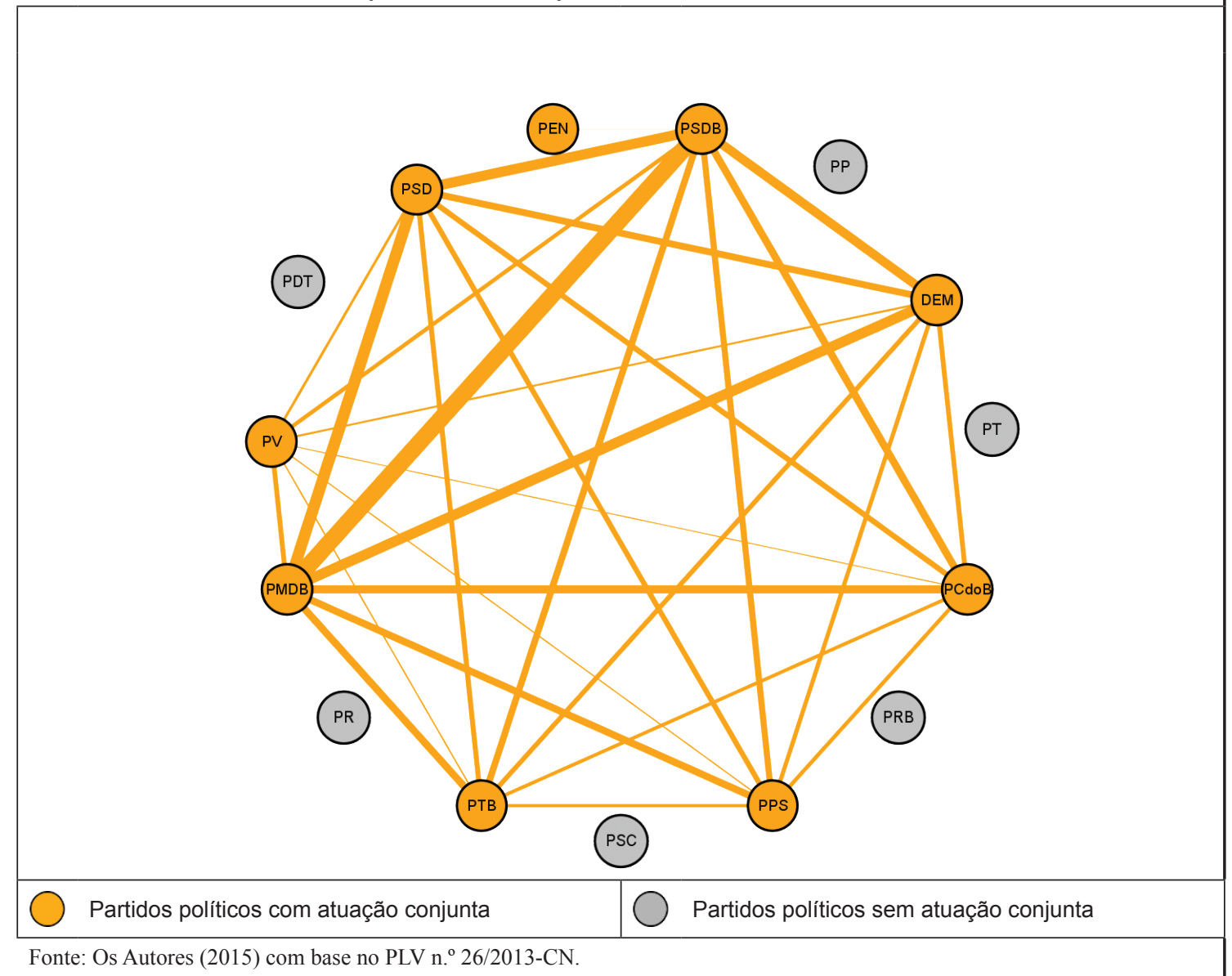

A atuação em conjunto objetivou afetar a agenda política para que as alternativas apresentadas pelos congressistas fossem contempladas na fase decisória. Noutros termos, este agrupamento latente se deu de forma coesa, com a finalidade de ampliar o potencial de atuação dos grupos no convencimento dos decisores políticos ${ }^{2}$.

Conforme se infere do Gráfico 1, dentre os 15 partidos políticos que, por meio de seus representantes, apresentaram proposições de emenda ao PLV n. ${ }^{\circ}$ 26/2013-CN, identificou-se a participação conjunta de parlamentares vinculados a 09 partidos políticos. Revelada esta atuação em grupo, por força das justificativas comuns (idênticas ou similares), foi possível formar dois conjuntos de parlamentares: $O$ primeiro, composto por 17 integrantes vinculados a 08 partidos políticos distintos; e o segundo, formado por apenas dois parlamentares integrantes de dois partidos políticos. Um dos partidos políticos que pertence a este segundo conjunto também está representado no primeiro conjunto, mas por outros parlamentares. Portanto, são 19 parlamentares agindo ordenadamente, num universo de 71 parlamentares atuantes no PLV n. ${ }^{\circ}$ 26/2013-CN ${ }^{18}$.

O PMDB foi o partido político com maior força entre os grupos ao estabelecer um total de 533 laços com os demais partidos, à exceção do PEN. O PSDB, por sua vez, firmou 488 laços, estabelecendo-os com todos os partidos do conjunto. Por seu turno, o PEN é o partido que possui a menor força dentre os participantes do grupo, pois estabeleceu apenas um laço com o PSDB. Com exceção do PEN, todos os demais partidos pertencentes aos grupos de interesses estabeleceram relações entre si. 
A afinidade estabelecida entre os parlamentares afiliados aos partidos políticos referidos permite concluir que estes propuseram mais emendas que os partidos políticos que agiram individualmente. Isso se infere porque os parlamentares em atuação conjunta apresentaram 286 emendas, equivalente a $50,44 \%$ do total de emendas apresentadas $(567)^{18}$.

O Gráfico 2 demonstra a influência das proposições de emendas em cada área por partido político, de onde se extrai que os parlamentares em atuações conjuntas ofertaram 48,91\% das proposições de emendas em relação às três áreas que mais receberam proposições (áreas 1, 2 e 3). Estas três áreas foram o foco de atenção dos grupos de interesses, pois do total de 782 proposições por eles apresentadas, 673 foram direcionadas para as três áreas identificadas, o equivalente a 86,06\% dos esforços do grupo ${ }^{18}$.

Desta análise, em relação à totalidade das proposições de emendas acolhidas, 8,11\% decorreu do exercício individual dos parlamentares. Já a atuação em equipe obteve 9,35\% de êxito. Esses números demonstram que a atuação em grupo obteve maior taxa de sucesso em relação ao desempenho singular dos parlamentares, pois as propostas oferecidas em conjunto foram mais eficazes $^{18}$.

\section{GRÁFICO 2 - INFLUÊNCIA DA ATUAÇÃO CONJUNTA DOS PARLAMENTARES NA PROPOSIÇÃO DE EMENDAS: ÁREAS POR PARTIDO POLÍTICO}

\begin{tabular}{|l|l|l|} 
Totalidade das proposições de emendas: & Influência da atuação conjunta nas proposições de \\
emendas: Áreas por partido político \\
Áreas por partido político
\end{tabular}


Em que pesem estes percentuais serem próximos, a grande diferença reside na quantidade de parlamentares envolvidos. Apenas 19 congressistas atuaram conjuntamente. Por outro lado, o restante dos participantes que agiram de maneira isolada, totaliza 67 parlamentares, os quais foram menos exitosos em comparação àqueles que desenvolveram suas atividades coletivamente ${ }^{18}$.

A atuação conjunta permitiu que $76,85 \%$ das proposições de emendas apresentadas em relação à área 3 , referente à autorização para funcionamento de cursos de medicina, fossem acolhidas. No entanto, o grupo não obteve o mesmo êxito em relação às Áreas 1 e 2, onde, respectivamente, $84 \%$ e $100 \%$ das proposições de emendas apresentadas foram rejeitadas ${ }^{18}$.

Enfim, esta análise permitiu identificar a forte atuação dos parlamentares envolvidos com a finalidade de alterar, em alguma medida, o teor da MPV n. ${ }^{\circ}$ 621/2013. Diante disso, torna-se relevante seguir adiante para compreender como se deu o acoplamento dos fluxos para a formulação do Programa Mais Médicos.

\section{A JANELA DE OPORTUNIDADES E O ACOMPLAMENTO DOS FLUXOS PARA A FORMULAÇÃO DO PROGRAMA MAIS MÉDICOS}

A reunião dos fluxos de problemas, de soluções e de política, que fluem separadamente, ocorre em momentos críticos. A esta reunião é atribuído o nome de acoplamento que ocorre no momento de abertura da janela política, conforme ilustra a Figura 1, anteriormente apresentada ${ }^{2}$.

A formulação do Programa Mais Médicos enquadra-se perfeitamente nesta estrutura, pois uma vez encontradas as possíveis soluções para o problema evidenciado, fortemente influenciadas pela interpretação dos agentes políticos ao humor nacional, as forças políticas movimentaram-se para realizar o acoplamento dos fluxos. A abertura da janela de oportunidades políticas, nesse contexto, foi imprevisível e a elevação do tema em referência à agenda política deu-se de forma fugaz, pois todos os fluxos corriam separados e livremente.

Os membros do Poder Executivo pretenderam fazer crer que o humor nacional foi o propulsor das ações dos agentes políticos vinculados ao próprio Poder Executivo e, posteriormente, ao Poder Legislativo, para a formulação do Programa. Ou seja, os três fluxos estavam desenvolvidos e prontos, cujas mobilizações sociais de junho de 2013, no entender dos agentes políticos envolvidos na formulação do Programa Mais Médicos, foram a alavanca utilizada para acoplá-los.

A confluência dos fluxos realizada pela Comissão Mista do Congresso Nacional, junto ao PLV n. ${ }^{\circ}$ 26/2013-CN, objetivou otimizar o texto da MPV n. ${ }^{\circ}$ 621/2013 e reformá-la em alguns aspectos. Essa movimentação parlamentar, porém, não ficou livre de incongruências em relação ao processamento e à análise das proposições de emendas apresentadas ${ }^{18}$.

A análise realizada pela Comissão Mista sobre as proposições de emendas parlamentares sofreu de algumas imprecisões ao não observar a homogeneidade dos dispositivos, recaindo nas seguintes 
impropriedades identificadas: proposições de emendas idênticas foram: $\boldsymbol{i}$ ) acolhidas e rejeitadas; $\boldsymbol{i i})$ acolhidas e não contempladas na redação final da Lei n. ${ }^{\circ}$ 12.871/2013; iii) antagônicas e acolhidas; iv) acolhidas e, ao mesmo tempo, rejeitadas pela relatoria, embora contrária aos objetivos perseguidos pelo Programa Mais Médicos e que foram relatadas como aprovadas no Ofício n. ${ }^{\circ}$ 028/MPV-621/2013 e na Mensagem n. ${ }^{\circ}$ 276/13 ${ }^{18}$.

Tudo isso comprova a fragilidade do PLV n. ${ }^{\circ}$ 26/2013-CN em relação à formulação de um programa de saúde pública de longo alcance. Ademais, uma sistematização dos resultados verificados nesta análise permite concluir que o parecer exarado pela Comissão Mista do Congresso Nacional acolheu parcialmente as contribuições apresentadas pelos legisladores ao selecionar, dentre as alternativas apresentadas, aquelas que - em sua fundamentação - considerou as mais adequadas à conversão da MPV n. ${ }^{\circ}$ 621/2013 na Lei n. ${ }^{\circ} 12.871 / 2013^{24}$.

Esta alteração inserida sobre a compreensão da política pública de saúde, especialmente pela perspectiva da reestruturação dos cursos de graduação em medicina e da ampliação do acesso à população, seguindo o entendimento de Kingdon, gerará um 'spillover', isto é, um transbordamento ou repercussão do tema sobre uma cadeia de eventos correlatos da saúde pública nacional frente ao estabelecimento de um novo princípio que norteará as ações políticas a partir de então².

Em síntese, a primazia atribuída à abertura de janela de oportunidades analisada, no âmbito da saúde pública nacional, está muito mais afeta aos critérios burocráticos de formação médica que aos critérios estruturais da saúde pública nacional estabelecidos constitucionalmente.

\section{CONSIDERAÇÕES FINAIS}

Esse artigo centrou-se na investigação do Programa Mais Médicos, enquanto uma política pública de saúde destinada à ampliação de atendimento junto à atenção básica. Para tanto, os ensinamentos trazidos por John Kingdon, criador do Modelo de Múltiplos Fluxos, permitiram decifrar os meandros da etapa pré-decisória de elaboração deste programa de saúde, com ênfase no processo legislativo, onde foi possível identificar a proeminência dos problemas, das alternativas e dos atores envolvidos.

Os agentes políticos atribuíram uma interpretação relacional da atuação legiferante extraordinária exercida pela Presidente da República, por meio da MPV n. ${ }^{\circ}$ 621/2013, ao aumento das exigências sociais, políticas e econômicas. Estes agentes, bem como os decision makers, detém os instrumentos capazes de perceber e mensurar o humor nacional ${ }^{2}$.

No caso em exame, as mobilizações de junho de 2013 foram o ápice e, ao mesmo tempo, o evento desencadeador da reemergência do tema e da abertura da janela de oportunidades para elevar o tema atinente à ampliação do acesso à saúde pública ao debate político².

O Programa Mais Médicos, nos moldes instituído, produz três novas mudanças na política 
sanitária nacional e sua interface com o ensino da medicina: i) aperfeiçoa médicos na área de atenção básica de saúde; ii) estabelece novos parâmetros para a ordenação da formação de recursos humanos médicos; iii) amplia a oferta de vagas para os cursos de graduação em medicina e residência médica, estabelecendo-os em regiões consideradas prioritárias para o SUS.

Atribuir ao Programa Mais Médicos uma conotação de política de governo constitui um inconveniente à sociedade ante a ausência de continuidade no fornecimento do serviço. Além disso, a ampliação na formação de recursos humanos, por si só, é insuficiente para garantir o atendimento universalizado de saúde. Assim, o desafio conferido ao Programa consiste em, efetivamente, disponibilizar saúde primária de forma universalizada. Para isso, uma nova ordem de inovação na gestão da saúde se desponta, exigindo-se a adoção de métodos de mensuração dos resultados inerentes à formulação deste Programa, considerando-se a saúde do paciente em todo ciclo de atendimento, perfazendo toda a carreira de complexidade clínica, tema este que exige um aprofundamento de estudo.

Portanto, não basta importar profissionais e formar mais médicos no âmbito interno. É imprescindível uma conformação sistematizada das metas a serem cumpridas pelos participantes do Programa Mais Médicos baseada no resultado atribuído à população. O maior desafio reside em expandir as atividades assistenciais da atenção básica de saúde atrelada ao ensino da medicina. Isso, consequentemente, pode repercutir na qualidade do atendimento ofertado à população.

\section{REFERÊNCIAS BIBLIOGRÁFICAS}

1 Cohen MD,March JG,Olsen, Johan P. A garbage can model of organizational choice. Administrative Science Quarterly, 1972 Mar 17 (1): 1-25.

2 Kingdon J. Agendas, Alternatives, and Public Policies. Update Edition (2.ed.), with an epilogue on Health Care. [Ebook]. Pearson New International Edition; 2013.1-273.

3 Capella ACN. Perspectivas teóricas sobre o processo de formulação de políticas públicas. Revista Brasileira de Informação Bibliográfica em Ciências Sociais 2006; 61: 20-40.

4 Brasil. Constituição da República Federativa do Brasil. Brasília: Senado Federal; 1988.Disponível em: http://www.planalto.gov.br/ccivil 03/constituicao/constituicaocompilado.htm.

5 Gonçalves E. O Estado e o princípio constitucional do direito à saúde. [Ebook]. São Paulo: Baraúna, 2011. 1-153.

6 Ribeiro J. Na TV, Dilma diz que Mais Médicos e recursos à educação são frutos de protestos Reuters Brasil. 2013 Out. Disponível em: http://br.reuters.com/article/ domesticNews/idBRSPE99701S20131008?sp=true. 
7 Quintiere A. Cinco pactos foram a resposta do governo federal aos protestos de junho. Agência Brasil. 2013 dez 13. Disponível em: http://memoria.ebc.com.br/agencia brasil/noticia/2013-12-31/cinco-pactos-foram-resposta-do-governo-federal-aos-protes tos-de-junho.

8 Maricato E et al. Cidades rebeldes: passe livre e as manifestações que tomaram as ruas do Brasil [Ebook]. São Paulo: Boitempo/Carta Maior; 2013. 1-112.

9 Padilha ARS, Oliva AM, Belchior MA. Exposição de Motivos Interministerial n. . 24-2013/ MS-MEC-MP vinculada à Lei Federal n. ${ }^{\circ}$ 12.871/2013. Brasília: 2013. 1-8.

10 Brasil. Lei n. ${ }^{\circ}$ 8.080, de 19 de setembro de 1990. Dispõe sobre as condições para a promoção, proteção e recuperação da saúde, a organização e o funcionamento dos serviços correspondentes e dá outras providências. Brasília: Diário Oficial da União; 1990 set. Disponível em: $\underline{\text { http:// }}$ www.planalto.gov.br/ccivil 03/leis/18080.htm.

11 Clève CM. Atividade legislativa do poder executivo. 2. ed., rev., atual. e ampl. São Paulo: Editora Revista dos Tribunais; 2000.1-325.

12 Brasil. Medida Provisória n. ${ }^{\circ}$ 621/2013, de 08 de julho de 2013. Institui o Programa Mais Médicos e dá outras providências. Convertida na Lei n. ${ }^{\circ}$ 12.871/2013. Brasília: Diário Oficial; 2013 jul. Disponível em:http:/www.planalto.gov.br/ccivil_03/ ato2011-2014/2013/Mpv/mpv621. $\underline{\mathrm{htm}}$.

13 Moreno AC, et al. Resultados das manifestações de junho. Globo.com. 28 jun. 2013. Disponível em: http://g1.globo.com/brasil/linha-tempo-manifestacoes2013/platb/.

14 AL' Hanatiy. O que restou das jornadas de junho? Gazeta do Povo. 24 nov. 2013. Disponível em: http://www.gazetadopovo.com.br/vidapublica/conteudo.phtml?id=14 27776\&tit=O-que -restou-das-jornadas-de-junho.

15 Silva JA. Processo constitucional de formação das leis. 2. ed., 2. tir.. São Paulo: Malheiros; 2007.1-374.

16 Liberati WD. Políticas Públicas no estado constitucional. São Paulo: Atlas; 2013.1-216.

17 Modena CA. O Processo legislativo, a medida provisória e a lei de conversão [Tese]. Curitiba: Universidade Federal do Paraná. 2004. 1-257.

18 Brasil. Congresso Nacional. Comissão Mista da Medida Provisória n. ${ }^{\circ}$ 621/2013. Projeto de Lei de Conversão n. ${ }^{\circ}$ 26/2013. Institui o Programa Mais Médicos; altera as Leis n. 8.745, de 09 dez. 1993, e 6.932, de 7 jul. 1981; dá outras providências. Transformado em norma jurídica com veto parcial. 2013. Disponível em: http://www.senado.gov.br/atividade/materia/detalhes. asp?p_cod_mate $=114601$. 
19 Modena CA. Medida provisória e controle parlamentar[Dissertação]. Curitiba: Universidade Federal do Paraná; 2000. 1-137

20 Ferreira Filho MG. Do processo legislativo. 7. ed., rev. e atual. São Paulo: Saraiva; 2012.1344.

21 Clève CM. Temas de direito constitucional. 2. ed., rev. e ampl. Belo Horizonte: Fórum; 2014. 1-503.

22.. Gephi Cet al. Gephi (Version 0.8.2-beta). Paris: The Gephi Consortium; 2014. Disponível em: $<$ https://gephi.github.io/>.

23 Gonçalves MCN. Regulação do lobby no Congresso Brasileiro: O Estado comparado do modelo norte-americano. 2012. Disponível em: http://bd.camara.gov.br/bd/bitstream/handle/bdcamara/8808/regulamentacao_lobby_goncalve.pdf? sequence $=1$

24 Brasil. Lei n. ${ }^{\circ}$ 12.871, de 22 de outubro de 2013. Institui o Programa Mais Médicos, altera as Leis no 8.745, de 9 de dezembro de 1993, e no 6.932, de 7 de julho de 1981, e dá outras providências. Brasília: Diário Oficial:2013 out. Disponível em: http://www.planalto.gov.br/ccivil_03/ ato2011-2014/2013/Lei/L12871.htm.

Artigo apresentado em 14-09-15 Artigo aprovado em 23-11-15 Artigo publicado no sistema em 30-12-15 